\title{
Resilience, depression, and quality of life in elderly individuals with chronic pain followed up in an outpatient clinic in the city of São Paulo, Brazil
}

This article was published in the following Dove Press journal: Journal of Pain Research

\author{
Marcia C Morete' \\ João Paulo C Solano² \\ Mario S Boff ${ }^{3}$ \\ Wilson J Filho ${ }^{3}$ \\ Hazem A Ashmawi ${ }^{3}$
}

'School of Medicine, University of São Paulo, Santos, São Paulo, Brazil; ${ }^{2}$ Department of Medicine, São Camilo University, São Paulo, Brazil; ${ }^{3}$ School of Medicine, University of São Paulo, São Paulo, Brazil
Correspondence: Marcia C Morete University of São Paulo, Parana Street, 291/03, Santos, São Paulo, Brazil Tel +55 I39 97447503 Email marciamorete@gmail.com
Purpose: In this study, we assessed resilience, depression, and quality of life in a group of elderly individuals with or without chronic pain.

Patients and methods: A cross-sectional study assessing elderly individuals followed up at a geriatrics outpatient clinic and divided into two groups: 54 elderly patients with chronic pain and 54 elderly with no chronic pain.

Results: The sample comprised mainly women (67.6\%), with mean age 79.9 years. The mean resilience index in the group with pain was 69.4 and, in the group with no pain, $80.1(P<0.001)$. Depression was observed in $35.2 \%$ of patients with chronic pain; there was no case of depression in those without chronic pain. Quality of life of the elderly with chronic pain was worse in all the domains assessed: physical, mental, emotional, social, vitality, and pain.

Conclusion: In the study sample, resilience was lower, depression was more frequent, and quality of life was worse in the group of elderly with chronic pain.

Keywords: pain, older, resilience

\section{Introduction}

As the population grows older, the prevalence of chronic health problems increases. Among these problems are several diseases and syndromes associated with chronic pain. ${ }^{1}$ In Brazil, in the $1960 \mathrm{~s}$, there were more than three million people of 60 or more years of age. In 2000, this portion of the population totaled more than 14 million people, almost $9 \%$ of the Brazilian population. Estimates by the Brazilian Institute of Geography and Statistics ${ }^{2}$ indicate that the elderly will represent $15 \%$ of the Brazilian population in 2020 , leaping to $18 \%$ in 2050 , which will correspond to approximately 38 million individuals. ${ }^{3}$ Within this context, Brazil will rank sixth among the countries with the largest number of elderly persons.

It is estimated that $20 \%-50 \%$ of elderly patients present with problems associated with pain. This proportion rises to $45 \%-80 \%$ of elderly inpatients. Pain control is inadequate in more than $50 \%$ of elderly, and over $25 \%$ die without obtaining its control. ${ }^{4-6}$ In the aged with cognitive dysfunctions, the diagnosis and treatment of pain may make the problems even worse; in part, this is aggravated by the greater difficulty in evaluating pain. $^{7-9}$

Among the elderly, chronic pain is the major complaint at outpatient clinics, and is the most frequent symptom in medical histories, occurring in $25 \%-50 \%$ of individuals. ${ }^{10-12}$ The most frequent pain complaints among the aged are osteoarthritis, especially in the lumbar or cervical region (about 65\%); musculoskeletal pain (roughly 40\%); 
peripheral neuropathy (usually due to diabetes or postherpetic neuralgia, 35\%); and chronic joint pain (15\%-25\%). ${ }^{13-15}$ The consequences of untreated pain can deeply affect the elderly person's quality of life. In addition to the physiological risks associated with untreated pain, other factors can be identified, such as depression ${ }^{16,17}$ and cognitive function compromise. ${ }^{18,19}$

Resilience is the capacity of remaining well, recovering, or even prospering in the presence of adversity. ${ }^{20,21}$ When considering resilience as a capacity to be developed normally under difficult or risky conditions, and taking into consideration that all people, to a greater or lesser degree, will have to face some of these conditions at some point, resilience and the interaction between the risk factors and protection factors are connected throughout the entire human life, whether in childhood, adolescence, adulthood, or old age. ${ }^{22}$

Resilience refers to the capacity of a system to adapt to (or to recover from) adversity. In this study, we concentrated on an individual aspect of resilience - the psychological aspect, which involves emotional flexibility and the availability of problem resolution strategies. ${ }^{23,24}$ In chronic pain, the psychological resources and the forms of dealing with adversity can facilitate adaptation styles, such as the acceptance of pain. ${ }^{25}$ Consequently, psychological resilience can protect against the adverse effects of chronic pain on psychological adjustment. ${ }^{26}$ However, due to life circumstances and the challenges associated with old age (such as personal loss, loss of social roles, and disease), ${ }^{27}$ resilience might operate differently in the elderly, in comparison with younger adults. ${ }^{28}$

The objective of this study was to compare the resilience of elderly Brazilians with and without chronic pain followed up at an outpatient clinic, and to correlate resilience with other important constructs in the elderly population: depression and quality of life.

\section{Materials and methods}

This study was approved by the Ethics Committee for Analysis of Research Projects of the Hospital of Clinics of The University of São Paulo Medical School (\# 499.917). A crosssectional design was used. The chosen population comprised aged individuals from a Multidisciplinary Care Group geared toward the elderly and seen at a geriatrics outpatient clinic. Inclusion criteria were as follows: older without impairment cognitive and age over 60 years, and exclusion criteria were as follows: disagree in participating in the study and the sample do not follow up in geriatric clinic. The sample was divided into two groups: 54 elderly participants with chronic pain and 54 participants with no chronic pain. The study was conducted from April to December 2017.
Resilience was evaluated by the Connor-Davidson Resilience scale (CD RISC) developed in 2003, composed of 25 items that assess the capacity of the patient to face adversities and overcome obstacles encountered during their life, with five answer categories $(0-4)$ grouped into four factors. The first factor was Tenacity (eleven items), which reflects the notion of personal competence; the second factor was Adaptability-tolerance (nine items) that has to do with tolerance of the negative effect and strengthening when facing stress. The third factor, Support (three items), reflects a positive acceptance of changes and safe relations. The fourth factor, Intuition (two items), reflects the control and confidence in one's instinct. The scale was translated to and validated for Brazilian Portuguese by Solano et al. ${ }^{32}$ The Geriatric Depression Scale, a scale designed by Sheikh and Yesavage, ${ }^{33}$ was used to evaluate depression. Quality of life was assessed by the SF-36 (The Medical Outcomes Study 36-item Short-Form Health Survey), translated into Portuguese by Ciconelli et al, ${ }^{34}$ which assesses eight domains, such as physical, social, and emotional aspects, as well as functional capacity, mental health, vitality, pain, and general health condition.

Initially, each participant's cognitive state was evaluated by the Mental State instrument (MEEM-Mini Mental) and, if dementia was absent, the patient was invited to participate in the study. If they agreed and signed the written informed consent term, they were included, and the questionnaires were applied while they waited to be seen by the geriatrician. Each instrument was explained to the participants, and the answers from the participants were recorded by the authors (MCM, $\mathrm{MSB}$ ). At the end of the questionnaire application, the elderly were questioned as to the presence of pain for more than 6 months on the same site, and thus they were allocated to the respective group: with and without chronic pain.

\section{Statistical analysis}

The values of the quantifiable variables were described by means and standard deviations, and minimum and maximum values. Even if the sample distribution of the values was asymmetric, the data were presented as means to allow better visualization of the results, since the median often coincided with the value of the first or the third quartile.

Quantitative variables were described as means \pm SD even when the distribution was asymmetric, to allow better visualization of the results, since the median often coincided with the value of the first or the third quartile. Minimum and maximum values were also presented. Categorical variables were described as absolute frequencies and percentages. For comparisons between groups regarding qualitative variables, 
we used chi-squared or Fisher's exact test. For quantitative variables, we used nonparametric Mann-Whitney since neither of the variables was normally distributed. The significance level was set at 5\%, and analyses were conducted with the R package (version 3.1.3).

\section{Results}

The sample comprised 108 elderly patients, 54 with pain, and 54 without. Seventy-three were women (67.6\%) and the mean age was 79.9 years. The pain sites most often reported were knees (24.1\%), lumbar region (20.4\%), shoulder (11.1\%), lower limbs (11.1\%), and upper limbs (9.3\%). Relationships between resilience, depression, and quality of life in the groups with and without pain, and relationships between resilience, depression, and quality of life among all the participants, were determined (Table 1).

Resilience was $80.1 \pm 7.4$ in the participants with no chronic pain, and $69.4 \pm 13.4$ in those with chronic pain $(P<0.001$; Table 2). The factorial structure of the CD RISC scale adapted for Brazil identified four main factors: Tenacity, Adaptability-Tolerance, Support, and Intuition. When analyzing these factors between the groups without and with pain, we observed higher values of Tenacity $(P<0.001)$, Adaptability-Tolerance $(P<0.001)$, Support $(P=0.009)$, and Intuition $(P=0.005)$ in the group without pain. In general, we noted less variability in the group without pain.

Depression was significantly more frequent among the elderly with pain $(P<0.001)$, and did not occur among those without chronic pain (Table 2 ). In the group with pain, qual-

Table I Characterization of the sample according to gender, marital status, and age in groups of elderly with and without chronic pain

\begin{tabular}{|c|c|c|c|}
\hline & \multicolumn{2}{|l|}{ Group } & \multirow[t]{3}{*}{$P$-value } \\
\hline & Without pain & With pain & \\
\hline & $n=54$ & $n=54$ & \\
\hline \multicolumn{4}{|l|}{ Gender n (\%) } \\
\hline Female & $30(55.6)$ & $43(79.6)$ & $0.013^{a}$ \\
\hline Male & $24(44.4)$ & II (20.4) & \\
\hline \multicolumn{4}{|l|}{ Marital status n (\%) } \\
\hline Single & $10(18.5)$ & $16(29.6)$ & $0.196^{b}$ \\
\hline Married & $20(37.0)$ & II (20.4) & \\
\hline Widower & $22(40.7)$ & $23(42.6)$ & \\
\hline Divorced & $2(3.7)$ & $4(7.4)$ & \\
\hline \multicolumn{4}{|l|}{ Age $n(\%)$} \\
\hline $65-75$ years & $12(22.2)$ & $21(39.6)$ & $0.15 \mathrm{I}^{\mathrm{a}}$ \\
\hline $75-80$ years & $17(33.3)$ & $14(26.4)$ & \\
\hline More than 80 years & $24(44.4)$ & $18(34.0)$ & \\
\hline
\end{tabular}

Notes: ${ }^{a}$ Chi-squared test. ${ }^{\text {}}$ Fisher's exact test. ity of life was worse in all SF-36 questionnaire domains (Table 3).

We noted an association between resilience and depression; the median resilience was 76 in the group without depression and 63 in the group with depression (Table 4). Lower resilience was observed in the participants with worse quality of life in the following domains: physical aspects, general health condition, pain, and mental health.

\section{Discussion}

This study aimed to compare the resilience of elderly people with and without chronic pain. It also analyzed other variables in the sample such as depression and quality of life. A total of 108 elderly individuals were evaluated, and 54 of them had complaints of chronic pain.

Investigations about resilience and chronic pain in the elderly are scarce. Our results showed that lower resilience was associated with chronic pain. When analyzing the four factors that comprise the Brazilian version of the CD RISC (Tenacity, Adaptability-Tolerance, Support, and Intuition), the differences between the two groups (with and without pain) proved consistent, especially in the Tenacity and Adaptability-tolerance factors. This appears to agree with the best psychometric properties found for Tenacity and Adaptability-tolerance facets in the validation study of the Brazilian version of the scale. ${ }^{29}$ Being a cross-sectional study, one cannot infer if chronic pain leads to decrease of resilience or lower resilience facilitates the development of chronic pain in older people.

The elderly with pain presented with more depression (35.2\% of patients) than those with no chronic pain. Some studies have shown that, among the elderly with persistent pain, the prevalence of depression is estimated as $19 \%$

Table 2 Frequency of depression and resilience in the groups of elderly with and without chronic pain

\begin{tabular}{|c|l|l|l|}
\hline \multirow{2}{*}{} & \multicolumn{2}{|l|}{ Group } & \multirow{2}{*}{ P-value } \\
\cline { 2 - 3 } & $\begin{array}{l}\text { Without pain } \\
\mathbf{( N = 5 4 )} \\
(\%)\end{array}$ & $\begin{array}{l}\text { With pain } \\
(\mathbf{N}=54) \\
(\%)\end{array}$ & \\
\hline $\begin{array}{c}\text { GDS } \\
\text { Negative }\end{array}$ & $54(100.0)$ & $35(64.8)$ & $<0.00 I^{\mathrm{a}}$ \\
$\begin{array}{c}\text { Positive } \\
\text { Resilience }\end{array}$ & $0(0.0)$ & $19(35.2)$ & \\
Mean (SD) & $80.1(7.4)$ & $69.4(13.4)$ & $<0.000 \mathrm{I}^{\mathrm{b}}$ \\
Minimum- & $(55.0-92.0)$ & $(24.0-93.0)$ & \\
Maximum & & & \\
\hline
\end{tabular}

Notes: a Chi-squared test. ${ }^{b}$ Nonparametric Mann-Whitney test. Abbreviation: GDS, Geriatric Depression Scale. 
Table 3 Distribution of quality of life aspects in the groups with and without pain according to SF-36

\begin{tabular}{|c|c|c|c|}
\hline \multirow[t]{2}{*}{ SF-36 } & \multicolumn{2}{|l|}{ Group } & \multirow[t]{2}{*}{$P$-value } \\
\hline & $\begin{array}{l}\text { Without pain } \\
n=54\end{array}$ & $\begin{array}{l}\text { With pain } \\
n=54\end{array}$ & \\
\hline $\begin{array}{l}\text { Physical aspects } \\
\text { Median (minimum, maximum) } \\
\text { (Ist quartile, } 3 r d \text { quartile) }\end{array}$ & $\begin{array}{l}100.0(0.0 ; 100.0) \\
(80.0 ; 100.0)\end{array}$ & $\begin{array}{l}0.0(0.0 ; 100.0) \\
(0.0 ; 75.0)\end{array}$ & $<0.001^{\mathrm{a}}$ \\
\hline $\begin{array}{l}\text { Social aspects } \\
\text { Median (minimum, maximum) } \\
\text { (Ist quartile, 3rd quartile) }\end{array}$ & $\begin{array}{l}100.0(50.0 ; 100.0) \\
(90.0 ; 100.0)\end{array}$ & $\begin{array}{l}87.50(0.0 ; 100.0) \\
(52.75 ; 100.0)\end{array}$ & $0.00 I^{a}$ \\
\hline $\begin{array}{l}\text { Functional capacity } \\
\text { Median (minimum, maximum) } \\
\text { (Ist quartile, 3rd quartile) }\end{array}$ & $\begin{array}{l}100.0(0.0 ; 100.0) \\
(90.0 ; 100.0)\end{array}$ & $\begin{array}{l}85.0(0.0 ; 100.0) \\
(60.0 ; 100.0)\end{array}$ & $0.00 \mathrm{I}^{\mathrm{a}}$ \\
\hline $\begin{array}{l}\text { Pain } \\
\text { Median (minimum, maximum) } \\
\text { (Ist quartile, 3rd quartile) }\end{array}$ & $\begin{array}{l}100.0(54.0 ; 100.0) \\
(90.0 ; 100.0)\end{array}$ & $\begin{array}{l}51.0(21.0 ; 100.0) \\
(41.0 ; 61.75)\end{array}$ & $<0.001^{a}$ \\
\hline $\begin{array}{l}\text { Emotional } \\
\text { Median (minimum, maximum) } \\
\text { (Ist quartile, 3rd quartile) }\end{array}$ & $\begin{array}{l}100.0(0.0 ; 100.0) \\
(90.0 ; 100.0)\end{array}$ & $\begin{array}{l}70.0(0.0 ; 100.0) \\
(0.0 ; 100.0)\end{array}$ & $0.00 I^{a}$ \\
\hline $\begin{array}{l}\text { Health condition } \\
\text { Median (minimum, maximum) } \\
\text { (Ist quartile, 3rd quartile) }\end{array}$ & $\begin{array}{l}90.0(37.0 ; 100.0) \\
(80.0 ; 97.0)\end{array}$ & $\begin{array}{l}78.0(0.0 ; 100.0) \\
(62.0 ; 87.0)\end{array}$ & $<0.001^{a}$ \\
\hline $\begin{array}{l}\text { Mental health } \\
\text { Median (minimum, maximum) } \\
\text { (Ist quartile, 3rd quartile) }\end{array}$ & $\begin{array}{l}90.0(0.0 ; 100.0) \\
(80.0 ; 100.0)\end{array}$ & $\begin{array}{l}60.0(0.0 ; 100.0) \\
(33.0 ; 88.0)\end{array}$ & $<0.001^{\mathrm{a}}$ \\
\hline $\begin{array}{l}\text { Vitality } \\
\text { Median (minimum, maximum) } \\
\text { (Ist quartile, 3rd quartile) }\end{array}$ & $\begin{array}{l}90.0(25.0 ; 100.0) \\
(80.0 ; 90.0)\end{array}$ & $\begin{array}{l}70.0(0.0 ; 100.0) \\
(40.0 ; 85.0)\end{array}$ & $<0.001^{a}$ \\
\hline
\end{tabular}

Note: ${ }^{a}$ Nonparametric Mann-Whitney test.

Table 4 Relationship between resilience and depression in both groups

\begin{tabular}{|l|l|l|l|}
\hline \multirow{2}{*}{} & \multicolumn{2}{|l|}{ GDS } & P-value \\
\cline { 2 - 3 } & Negative & Positive & \\
\hline Resilience $^{\mathrm{a}}$ & $76.00(24.00 ; 93.00)$ & $63.00(46.00 ; 84.00)$ & 0.009 \\
\hline
\end{tabular}

Note: ${ }^{2}$ Median (Ist quartile, 3rd quartile). Comparison by Mann-Whitney test. Abbreviation: GDS, Geriatric Depression Scale.

$28 \% .{ }^{30,31}$ Authors stated that $25 \%$ of elderly with persistent pain are at risk of depression and its consequences. ${ }^{32,33}$ In our sample, more than one-third of patients with pain presented depression, and suffered from both depression and chronic pain; however, no depression was identified in any participant without pain, using the GDS questionnaire.

We found that lower resilience was associated with depression. The relationship between low resilience and mood disorders has already been pointed out in some studies. ${ }^{34,35}$ Individuals with lower resilience present with greater vulnerability for developing depression and somatization. ${ }^{36-38}$ In a population of a Chinese community aged over 60 years, lower levels of resilience were significantly associated with higher levels of depressive symptoms. ${ }^{39}$

Quality of life of the elderly with pain was compromised in the eight domains evaluated. These findings are corroborated by several studies showing that quality of life related to health is lower in patients with chronic pain, compared with healthy individuals ${ }^{40-44}$ Some authors suggest that pain is the main cause of deteriorating quality of life. ${ }^{45}$

Regarding the association between resilience and quality of life, this study showed lower resilience in the following domains: physical, general health condition, mental health, and pain. However, there was no difference in functional capacity between the two groups.

This study identified a relationship between lower resilience and religiousness in its organizational aspect, which relates to attendance at religious meetings, such as masses and services. Among the forms of dealing with pain, religiousness and spirituality have proved very important. ${ }^{45}$

Resilience refers to the capacity to deal with and adapt in the face of adversity, and affects several aspects of life. Some authors state that individual and psychological 
resilience involves emotional flexibility and the availability of problem-solving strategies; in chronic pain, these resources may facilitate adaptive confrontation, such as acceptance of pain. ${ }^{23,24}$ Due to life circumstances and the challenges of advanced age, for instance, death, loss of social roles, and disease, ${ }^{27}$ resilience may operate differently in the elderly compared with younger adults. ${ }^{18}$ The hypothesis that aging adds to personal resilience, both in people with and without pain, would be plausible; chronic pain, however, could function as a disruptive stressor, an additional overload that would retard instead of increasing resilience. Nevertheless, an alternative explanation would be that the most resilient elderly would have a greater chance of falling into the group of elderly without pain, since they complain less (including of their own pain).

For most authors, resilience seems to play a significant role in confronting chronic pain, and to contribute to the development of internal resources that help a person deal in a positive manner with all adversities. An intervention study could be useful to assess the value of introducing techniques to enhance resilience in this population.

\section{Conclusion}

The study concluded that elderly people with chronic pain have lower resilience, more depression, and lower QOL than those without chronic pain.

The findings of the study suggest that resilience may be an important aspect in the process of confronting chronic pain; its evaluation might contribute to an integral approach to the elderly patient with chronic pain.

\section{Acknowledgment}

The authors certify that this work is novel.

\section{Disclosure}

The present study is a doctoral research at the University of São Paulo in Brazil, and there are no conflicts of interest in this study. This study kept the ethical standards of research with humans required in Brazil (Resolution 466/12). The authors report no conflicts of interest in this work.

\section{References}

1. Santos FC, Polianna Mara Rodrigues de S, Nogueira SAC, Lorenzet IC, Barros BF, Dardin LP. Programa de autogerenciamento da dor crônica no idoso: estudo piloto. Revista Dor. 2011;12(3):209-214.

2. Ministério do Planejamento, Orçamento e Gestão, Instituto Brasileiro de Geografia e Estatística. Síntese de Indicadores Sociais: Uma Análise das Condições de Vida da População Brasileira 2010. Rio de Janeiro: IBGE; 2010. Portuguese.

3. Planejamento Mdo. Orçamento e Gestão, Instituto Brasileiro de Geografia e Estatística. Perfil dos Idosos Responsáveis Pelos Domicílios no Brasil 2000. Rio de Janeiro: IBGE; 2002.
4. Chopra A. Pain management in the older patient. Clin Geriatr. 2006;14(3):40-46.

5. AGS Panel on Persistent Pain in Older Persons. The management of persistent pain in older persons. J Am Geriatr Soc. 2002;50(6 Suppl):205-224.

6. American Geriatrics Society Panel on Pharmacological Management of Persistent Pain in Older Persons. Pharmacological management of persistent pain in older persons. J Am Geriatr Soc. 2009;57(8):1331-1346.

7. Karp JF, Shega JW, Morone NE, Weiner DK. Advances in understanding the mechanisms and management of persistent pain in older adults. $\mathrm{Br}$ J Anaesth. 2008;101(1):111-120.

8. Fine PG. Chronic pain management in older adults: special considerations. J Pain Symptom Manage. 2009;38(2 Suppl):S4-S14.

9. Kaasalainen S, Molloy DW. Pain and aging. Geriatrics today. J Am Geriatr Soc. 2001;4:32-37.

10. Barr JO. Controle conservador da dor no paciente idoso. In: Guccione AA, editor. Fisioterapia Geriátrica. 2nd ed. Rio de Janeiro: Guanabara Koogan; 2002:333-356.

11. Brummel-Smith K, London MR, Drew N, Krulewitch H, Singer C, Hanson L. Outcomes of pain in frail older adults with dementia. J Am Geriatr Soc. 2002;50(11):1847-1851.

12. Smith J, Borchelt M, Maier H, Jopp D. Health and Well-Being in the Young Old and Oldest Old. J Soc Issues. 2002;58(4):715-732.

13. Donald IP, Foy C. A longitudinal study of joint pain in older people. Rheumatology. 2004;43(10):1256-1260.

14. Mailis-Gagnon A, Nicholson K, Yegneswaran B, Zurowski M. Pain characteristics of adults 65 years of age and older referred to a tertiary care pain clinic. Pain Res Manag. 2008;13(5):389-394.

15. Denard PJ, Holton KF, Miller J, et al. Back pain, neurogenic symptoms, and physical function in relation to spondylolisthesis among elderly men. Spine J. 2010;10(10):865-873.

16. Herr KA, Mobily PR. Chronic pain and depression. J Psychosoc Nurs Ment Health Serv. 1992;30(9):7-12.

17. Parmelee PA, Smith B, Katz IR. Pain complaints and cognitive status among elderly institution residents. J Am Geriatr Soc. 1993;41(5):517-522.

18. Duggleby W, Hicks D, Nekolaichuk C, et al. Hope, older adults, and chronic illness: a metasynthesis of qualitative research. J Adv Nurs. 2012;68(6):1211-1223.

19. Hurley AC, Volicer BJ, Hanrahan PA, Houde S, Volicer L. Assessment of discomfort in advanced Alzheimer patients. Res Nurs Health. 1992;15(5):369-377.

20. Berkman LF, Seeman TE, Albert M, et al. High, usual and impaired functioning in community-dwelling older men and women: findings from the MacArthur Foundation Research Network on Successful Aging. J Clin Epidemiol. 1993;46(10):1129-1140.

21. Ryff CD, Singer B, Love GD, Essex MJ. Resilience in adulthood and later life: defining features and dynamic processes. In: Lomranz J, editor. Handbook of Aging and Mental Health: an Integrative Approach. New York: Plenum Press; 1998:69-96.

22. Leipold B, Greve W. Resilience: A conceptual bridge between coping and development. Eur Psychol. 2009;14(1):40-50.

23. Wagnild G. Resilience and successful aging. Comparison among low and high income older adults. J Gerontol Nurs. 2003;29(12):42-49.

24. Waugh CE, Thompson RJ, Gotlib IH. Flexible emotional responsiveness in trait resilience. Emotion. 2011;11(5):1059-1067.

25. Ramírez-Maestre C, Esteve R, López AE. The path to capacity: resilience and spinal chronic pain. Spine. 2012;37(4):E251-E258.

26. Ruiz-Párraga GT, López-Martínez AE, Gómez-Pérez L. Factor structure and psychometric properties of the resilience scale in a spanish chronic musculoskeletal pain sample. J Pain. 2012;13(11):1090-1098.

27. Hildon Z, Smith G, Netuveli G, Blane D. Understanding adversity and resilience at older ages. Sociol Health Illn. 2008;30(5):726-740.

28. Duggleby W, Lander J. Patient-controlled analgesia for older adults. Clin Nurs Res. 1992;1(1):107-113.

29. Solano JP, Bracher ES, Faisal-Cury A, et al. Factor structure and psychometric properties of the Connor-Davidson resilience scale among Brazilian adult patients. Sao Paulo Med J. 2016;134(5): 400-406. 
30. Sheikh JI, Yesavage JA. Geriatric depression scale (GDS): recent evidence and development of a shorter version. Clin Gerontol. 1986;5(1-2):165-173.

31. Ciconelli RM, Ferraz MB, Santos W, Meinão I, Quaresma MR. Tradução para a língua portuguesa e validação do questionário genérico de avaliação de qualidade de vida SF-36 (Brasil SF-36). Rev Bras Reumatol. 1999;39(3):143-150.

32. Gleicher Y, Croxford R, Hochman J, Hawker G. A prospective study of mental health care for comorbid depressed mood in older adults with painful osteoarthritis. BMC Psychiatry. 2011;11(1):147.

33. Tektonidou MG, Dasgupta A, Ward MM. Suicidal ideation among adults with arthritis: prevalence and subgroups at highest risk. Data from the 2007-2008 National Health and Nutrition Examination Survey. Arthritis Care Res. 2011;63(9):1322-1333.

34. Lavin R, Park J. Depressive symptoms in community-dwelling older adults receiving opioid therapy for chronic pain. J Opioid Manag. 2011;7(4):309-319.

35. Hanssen DJ, Naarding P, Collard RM, Comijs HC, Oude Voshaar RC. Physical, lifestyle, psychological, and social determinants of pain intensity, pain disability, and the number of pain locations in depressed older adults. Pain. 2014;155(10):2088-2096.

36. Pollack MH, Stein MB, Davidson JRT, Ginsberg DL. New challenges for anxiety disorders: Where treatment, resilience, and economic priority converge. CNS Spectr. 2004;9(04):1-4.

37. Degnan KA, Fox NA. Behavioral inhibition and anxiety disorders: multiple levels of a resilience process. Dev Psychopathol. 2007;19(3):729-746.
38. Aroian KJ, Schappler-Morris N, Neary S, Spitzer A, Tran TV. Psychometric evaluation of the Russian Language version of the Resilience Scale. J Nurs Meas. 1997;5(2):151-164.

39. Heilemann MV, Lee K, Kury FS. Psychometric properties of the Spanish version of the Resilience Scale. J Nurs Meas. 2003;11(1):61-72.

40. Lin X, Haralambous B, Pachana NA, et al. Screening for depression and anxiety among older Chinese immigrants living in Western countries: The use of the Geriatric Depression Scale (GDS) and the Geriatric Anxiety Inventory (GAI. Asia Pac Psychiatry. 2016;8(1):32-43.

41. Bauer H, Emeny RT, Baumert J, Ladwig KH. Resilience moderates the association between chronic pain and depressive symptoms in the elderly. Eur J Pain. 2016;20(8):1253-1265.

42. Otto M, Bach FW, Jensen TS, Sindrup SH. Health-related quality of life and its predictive role for analgesic effect in patients with painful polyneuropathy. Eur J Pain. 2007;11(5):572-578.

43. Pagano T, Matsutani LA, Ferreira EA, Marques AP, Pereira CA. Assessment of anxiety and quality of life in fibromyalgia patients. Sao Paulo Med J. 2004;122(6):252-258.

44. Bergman S, Jacobsson LT, Herrström P, Petersson IF. Health status as measured by SF-36 reflects changes and predicts outcome in chronic musculoskeletal pain: a 3-year follow up study in the general population. Pain. 2004;108(1-2):115-123.

45. Stewart AL, Greenfield S, Hays RD, et al. Functional status and wellbeing of patients with chronic conditions. Results from the Medical Outcomes Study. JAMA. 1989;262(7):907-913.
Journal of Pain Research

\section{Publish your work in this journal}

The Journal of Pain Research is an international, peer reviewed, open access, online journal that welcomes laboratory and clinical findings in the fields of pain research and the prevention and management of pain. Original research, reviews, symposium reports, hypothesis formation and commentaries are all considered for publication.

\section{Dovepress}

The manuscript management system is completely online and includes a very quick and fair peer-review system, which is all easy to use. Visit http://www.dovepress.com/testimonials.php to read real quotes from published authors. 